\title{
Green synthesis and characterization of $\mathrm{Ag}_{1 / 2} \mathrm{Al}_{1 / 2} \mathbf{T i O}_{3}$ nanoceramics
}

\author{
SANDEEP KUMAR ${ }^{1}$, ANAL K. JHA ${ }^{1,2}$, K. PRASAD ${ }^{2,3 *}$ \\ ${ }^{1}$ University Department of Chemistry, T.M. Bhagalpur University, Bhagalpur 812 007, India \\ ${ }^{2}$ Aryabhatta Centre for Nanoscience and Nanotechnology, Aryabhatta Knowledge University, Patna 800001 , India \\ ${ }^{3}$ University Department of Physics, T.M. Bhagalpur University, Bhagalpur 812 007, India
}

Single phase silver aluminum titanate $\left(\mathrm{Ag}_{1 / 2} \mathrm{Al}_{1 / 2}\right) \mathrm{TiO}_{3}$, later called AAT, nanoceramic powder (particle size 2 to $7.5 \mathrm{~nm}$ ) was synthesized by a low-cost, green and reproducible tartaric acid gel process. X-ray, FT-IR, energy dispersive X-ray and high resolution transmission electron microscopy analyses were performed to ascertain the formation of AAT nanoceramics. X-ray diffraction data analysis indicated the formation of monoclinic structure having the space group P2/m(10). UV-Vis study revealed the surface plasmon resonance at $296 \mathrm{~nm}$. Dielectric study revealed that AAT nanoceramics could be a suitable candidate for capacitor applications and meets the specifications for "Z7R" of Class I dielectrics of Electronic Industries Association. Complex impedance analyses suggested the dielectric relaxation to be of non-Debye type. To find a correlation between the response of the real system and idealized model circuit composed of discrete electrical components, the model fittings were performed using the impedance data. Electric modulus studies supported the hopping type of conduction in AAT. The correlated barrier hopping model was employed to successfully explain the mechanism of charge transport in AAT. The ac conductivity data were used to evaluate the density of states at Fermi level and minimum hopping length of the compound.

Keywords: electronic materials; oxides; chemical synthesis; dielectric properties; electrical properties

(C) Wroclaw University of Technology.

\section{Introduction}

In recent years, a number for lead-free perovskite $\mathrm{ABO}_{3}$-type materials have been investigated for their possible technological applications [1-7]. The different principles of chemistry, which can be combined (viz. ionic radii, valence state, tolerance factor, etc.) to obtain numerous complex perovskite oxides with the mixed-cation formula, such as $\left(\mathrm{A}^{\prime} \mathrm{A}^{\prime \prime} \ldots\right) \mathrm{BO}_{3}, \mathrm{~A}\left(\mathrm{~B}^{\prime} \mathrm{B}^{\prime \prime} \ldots\right) \mathrm{O}_{3}$ or $\left(\mathrm{A}^{\prime} \mathrm{A}^{\prime \prime} \ldots\right)\left(\mathrm{B}^{\prime} \mathrm{B}^{\prime \prime} \ldots\right) \mathrm{O}_{3}$ have a variety of interesting properties, designed for many electronic and/or microelectronic devices. Also, it has been observed that modifications either at Aor B-site plays an important role in tailoring various properties of complex perovskites as the materials' properties depend mainly on the size difference of pseudo-cation $\left(\mathrm{A}^{\prime} \mathrm{A}^{\prime \prime} \ldots\right)^{2+}$ and/or $\left(\mathrm{B}^{\prime} \mathrm{B}^{\prime \prime} \ldots\right)^{4+}$ as well as on the difference in

*E-mail: k.prasad65@gmail.com their valence states. It was observed that sodium bismuth titanate, $\left(\mathrm{Na}_{0.5} \mathrm{Bi}_{0.5}\right) \mathrm{TiO}_{3}$, which shows strong ferroelectric properties, is considered to be an excellent candidate as a key material for lead-free piezoelectric applications [8-10]. Recent reports on the identical silver-based compounds, such as $\left(\mathrm{Ag}_{1 / 2} \mathrm{Bi}_{1 / 2}\right) \mathrm{TiO}_{3}$ [11, 12], $\left(\mathrm{Ag}_{1 / 2} \mathrm{Fe}_{1 / 2}\right) \mathrm{TiO}_{3}$ [13], $\left(\mathrm{Ag}_{1 / 2} \mathrm{Al}_{1 / 2}\right) \mathrm{TiO}_{3}$ [14], $\mathrm{NaNbO}_{3}-\mathrm{Bi}_{0.5} \mathrm{~A}_{0.5} \mathrm{TiO}_{3} \quad(\mathrm{~A}=\mathrm{Li}, \quad \mathrm{Na}, \quad \mathrm{K}$, Ag) [15], $\quad \mathrm{Bi}_{0.5}\left(\mathrm{Na}_{1-x-y} \mathrm{~K}_{x} \mathrm{Ag}_{y}\right)_{0.5} \mathrm{TiO}_{3} \quad$ [16], $\mathrm{Bi}_{0.5} \mathrm{Na}_{0.5} \mathrm{TiO}_{3}-\mathrm{BaTiO}_{3}-\mathrm{Bi}_{0.5} \mathrm{Ag}_{0.5} \mathrm{TiO}_{3} \quad$ [17], $\mathrm{Bi}_{0.5} \mathrm{Na}_{0.5} \mathrm{TiO}_{3}-\mathrm{Bi}_{0.5} \mathrm{~K}_{0.5} \mathrm{TiO}_{3}-\mathrm{Bi}_{0.5} \mathrm{Ag}_{0.5} \mathrm{TiO}_{3}$ $[18,19]$ also showed excellent electrical properties. Further, it has been observed that ceramic powders synthesized using conventional solid-state method lead to the formation of large grains, which are difficult to disperse and affect the sintering properties. In recent years, alternative methods for the powder synthesis, such as sol-gel, hydrothermal, biosynthesis, molten salt and different soft-chemical methods have been developed by 
many workers [13, 14, 20-29]. In further search of new lead-free alternative, one such material in this series is perovskite $\left(\mathrm{Ag}_{1 / 2} \mathrm{Al}_{1 / 2}\right) \mathrm{TiO}_{3}$. The material is mechanically tough and lead-free. Extensive literature survey indicated that no attempt, to the authors' knowledge, has been made so far by any group to study $\left(\mathrm{Ag}_{1 / 2} \mathrm{Al}_{1 / 2}\right) \mathrm{TiO}_{3}$ nanoceramics (abbreviated as AAT-nc).

The study on electrical conductivity in such materials is very important as the associated physical properties are dependent on the nature and magnitude of conductivity. Residual conductivity in the bulk of the grains of such materials has been found to be around $10^{-7} \mathrm{~S} \cdot \mathrm{m}^{-1}$ in the operating temperature region. The high insulating property is caused mainly due to the fact that grain boundaries in the dielectric material act as high resistive barriers for the cross transport of charge carriers. In case of nanoceramics, due to its high surfaceto-volume ratio, grain boundaries can be expected to exert greater influence over electrical/dielectric properties than in conventional microcrystalline ceramics. Therefore, proper understanding of the effect of grain boundaries for evaluating overall behavior of the ceramic samples is important. Complex impedance spectroscopy has been recognized as a non-destructive powerful technique to study the microstructure and the electrical properties of solids. Thus, the dynamics of ionic movement and contributions of various microstructure elements, such as grain, grain boundary and interface polarization to total electric response in polycrystalline solids can be identified by this technique. It also enables us to evaluate the nature of dielectric relaxation and the relaxation frequency of the material.

Accordingly, the present work reports the synthesis (using tartaric acid gel method) and structural (X-ray and its Rietveld analysis), high resolution transmission electron microscopy, UV-Vis and Fourier transformed infrared spectroscopy studies of AAT-nc. The tartrate method is a kind of sol-gel method using tartaric acid as a complexing agent. The complexation of metal cations by free carboxyl groups allows reactants mixing at molecular level and consequently leads to uniform, fine powders with high purity at relatively low temperatures.
Moreover, this soft-chemical synthetic process is totally green, easily controlled and convenient in comparison with other methods. Furthermore, the dielectric, impedance and ac conductivity studies of AAT-nc, which is mechanically tough and ensures environment-friendly applications, have been carried out. For better understanding the correlation between the response of the real system and idealized model circuit composed of discrete electrical components, circuit model fittings, using the impedance data, have been carried. The correlated barrier hopping model has been applied to the ac conductivity data to ascertain the conduction mechanism of charge transport in the system. Also, the ac conductivity data have been used to estimate the density of states at Fermi level and minimum hopping length. Furthermore, an effort has been made to explain the mechanism for the soft-chemical synthesis of AAT-nc using simple principles of organic chemistry.

\section{Experimental}

\subsection{Synthesis of $\left(\mathrm{Ag}_{1 / 2} \mathrm{Al}_{1 / 2}\right) \mathrm{TiO}_{3}$ nano- particles}

Fine AAT-nc powder was prepared by the tartaric acid gel method using reagent grade $\left(99.9 \%+\right.$ pure) chemicals: $\mathrm{AgNO}_{3}$ (Merck, Germany), $\mathrm{Al}\left(\mathrm{NO}_{3}\right)_{3} \cdot 9 \mathrm{H}_{2} \mathrm{O}$ (Across, USA), titanium (IV) n-Butoxide (Across, USA) and tartaric acid as starting materials. A weighed amount of tartaric acid was first dissolved into deionized water. Aqueous ammonia was dripped slowly to adjust the $\mathrm{pH}$ value of the solution between 7 and 8 . After stirring at $70{ }^{\circ} \mathrm{C}$ for $1 \mathrm{~h}$, a yellowish liquid was obtained. Then, $\mathrm{AgNO}_{3}, \mathrm{Al}\left(\mathrm{NO}_{3}\right)_{3} \cdot 9 \mathrm{H}_{2} \mathrm{O}$, titanium (IV) n-Butoxide were weighed stoichiometrically in accordance with the formula $\left(\mathrm{Ag}_{1 / 2} \mathrm{Al}_{1 / 2}\right) \mathrm{TiO}_{3}$ and were added into the solution, followed by stirring at $70{ }^{\circ} \mathrm{C}$ for $1 \mathrm{~h}$ to prepare a transparent precursor solution. The precursor solution was dehydrated at $100{ }^{\circ} \mathrm{C}$ to form a sol. Subsequent heating at a higher temperature of $160{ }^{\circ} \mathrm{C}$ yielded a gel. The gel initially started swelling and produced a foamy precursor. The gel was pulverized and then heated at $300{ }^{\circ} \mathrm{C}$ for $2 \mathrm{~h}$ in air to get a carbonaceous 
mass. Finally, the carbonaceous mass was calcined at $700{ }^{\circ} \mathrm{C}$ for $5 \mathrm{~h}$. The schematic for the soft chemical synthesis of AAT-nc powder using tartaric acid gel method is detailed in Fig. 1. Completion of the reaction and formation of the desired compound was checked by X-ray diffraction technique.

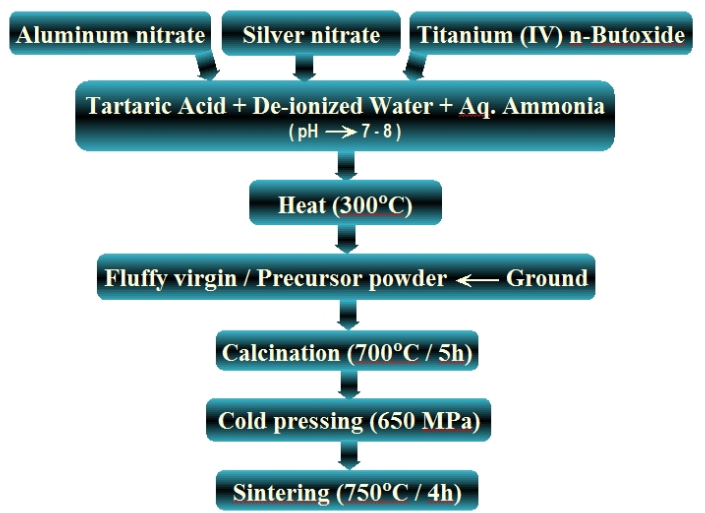

Fig. 1. Procedure for the soft-chemical synthesis of $\left(\mathrm{Ag}_{1 / 2} \mathrm{Al}_{1 / 2}\right) \mathrm{TiO}_{3}$ nanoceramics using tartaric acid gel method.

\subsection{Characterization}

The crystal structure was identified by powder $\mathrm{X}$-ray diffraction (XRD) analysis with $\mathrm{CuK} \alpha$ radiation (X'PERT-PRO, Pan Analytical). The XRD data for Rietveld analysis were collected over the range of $2 \theta=20$ to $80^{\circ}$ with a step size of $0.02^{\circ}$ with a count time of 2 s. The FullProf program was used for Rietveld structural refinement. TEM micrographs, selected area diffraction (SAED), lattice image and energy dispersive $\mathrm{X}$ ray (EDX) patterns of AAT-nc were obtained using a high resolution Bruker transmission electron microscope. The particle sizes were estimated from the TEM micrograph with the help of Image J software. The Fourier transformed infrared (FT-IR) spectrum of AAT-nc was collected in the transmission mode using a Perkin Elmer spectrum BX2 FT-IR spectrophotometer in the range of 400 to $4000 \mathrm{~cm}^{-1}$. The absorption spectrum of ultrasonically dispersed AAT-nc in absolute ethanol was obtained by a computer interfaced UV-Vis spectrophotometer (Hitachi AU-2700). A sintered pellet $\left(750{ }^{\circ} \mathrm{C}, 4 \mathrm{~h}\right)$ was polished and electroded with air-drying silver paste (SPI supplier, USA) to measure the electrical properties. Dielectric and impedance measurements were carried out using a computer-interfaced LCR Hi-Tester (HIOKI 353250, Japan). Further, the temperature coefficient of capacitance $\left(\mathrm{T}_{\mathrm{CC}}\right)$ which is an important parameter for the low-temperature dependence of capacitance was defined as: $\mathrm{T}_{\mathrm{CC}}=\frac{\mathrm{C}_{\mathrm{T}}-\mathrm{C}_{\mathrm{RT}}}{\mathrm{C}_{\mathrm{RT}}} \times 100$; where $\mathrm{C}_{\mathrm{T}}$ and $\mathrm{C}_{\mathrm{RT}}$ represent the values of capacitance at the elevated and at room temperature, respectively.

\section{Results and discussion}

The Rietveld refined XRD profile of AAT-nc powder synthesized using tartaric acid gel method is presented in Fig. 2. The results of Rietveld analysis reveal a monoclinic crystal structure having the space group P2/m(10). Single sharp peaks in XRD pattern of AAT, belonging to pure pervoskite phase are found and no other intermediate phase is found, which indicates the formation of a single phase compound. The XRD and refined structural parameters are depicted in Table 1. The adopted profile fitting procedure was minimizing the $\chi^{2}$-function. It can be seen that the observed and calculated profiles are perfectly matched $\left(\chi^{2}=1.298\right)$. Further, the presence of broad peaks in XRD pattern may be due the nanosizing effect in AAT-nc.

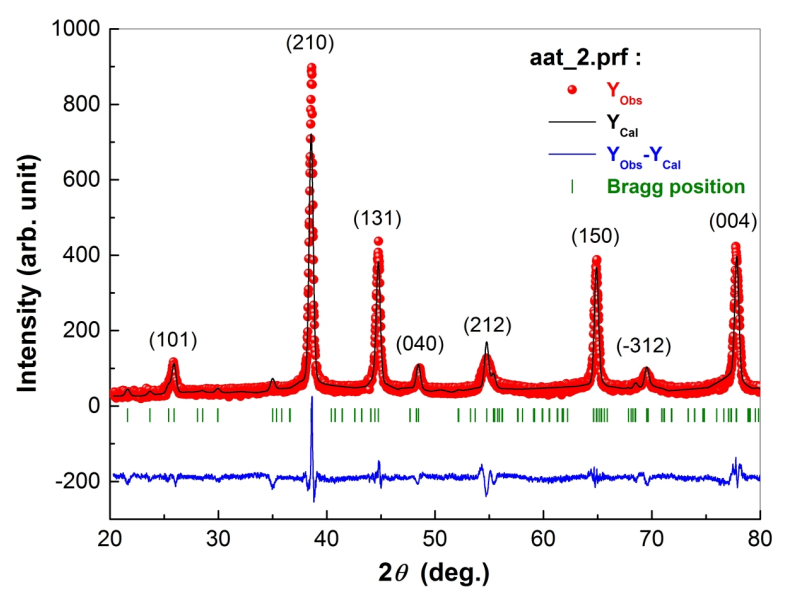

Fig. 2. Rietveld refined XRD pattern of $\left(\mathrm{Ag}_{1 / 2} \mathrm{Al}_{1 / 2}\right) \mathrm{TiO}_{3}$ nanoceramics in the space group P2/m(10). Symbols represent observed data points and solid lines their Rietveld fit. 


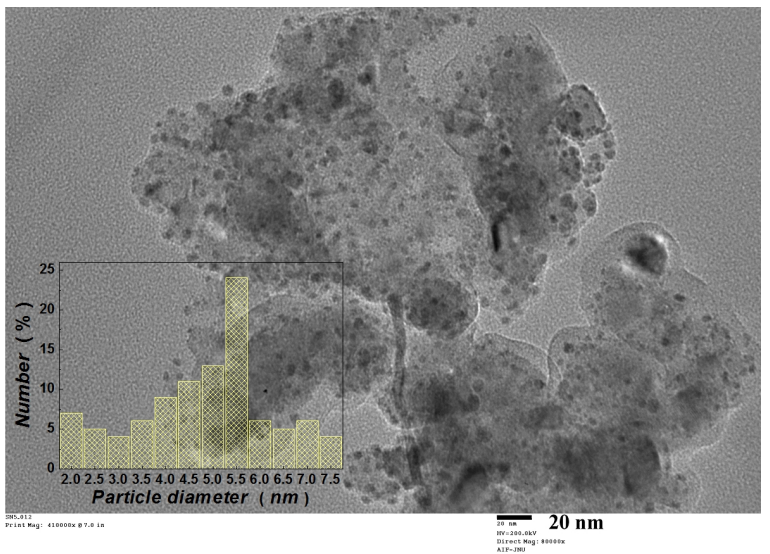

Fig. 3. TEM image and particle size distribution (inset) of $\left(\mathrm{Ag}_{1 / 2} \mathrm{Al}_{1 / 2}\right) \mathrm{TiO}_{3}$ nanoceramics.

The particle sizes and morphologies of AATnc powder fired at $700{ }^{\circ} \mathrm{C}$ were examined by HRTEM. As shown in Fig. 3, all AAT particles, which are almost spherical in shape are very small, with the sizes ranging between 2 to $7.5 \mathrm{~nm}$ (inset of Fig. 3). The average value of the particle size was estimated to be $4.82 \pm 0.05 \mathrm{~nm}$. The measurements of sizes were carried along the diameter of the particles. The difference in size may possibly be due to the agglomeration of individual nanoparticles being formed at different times.

Fig. 4 shows the EDX pattern and the insets: (a) TEM image of one particle, (b) SAED pattern and (c) lattice image of AAT-nc. All the peaks in the EDX pattern are perfectly assigned to the elements present in $\left(\mathrm{Ag}_{1 / 2} \mathrm{Al}_{1 / 2}\right) \mathrm{TiO}_{3}$. This clearly indicates the successful synthesis and purity of chemical composition of AAT-nc. The HR-TEM micrograph (inset of Fig. 4a) clearly shows individual nanoparticles, which are spherical in shape. The inset of Fig. $4 \mathrm{~b}$ illustrates Scherrer rings in the SAED pattern, which clearly indicates the formation of nanocrystalline particles of AAT. Indexing of SAED pattern revealed the monoclinic lattice structure, which is in agreement with XRD result. The inset in Fig. 4c clearly reveals that the lattice images of AAT-nc particles are monoclinic with a d-spacing of $0.233 \mathrm{~nm}$, corresponding to the (210) plane.

FT-IR analysis was used to characterize the synthesized AAT-nc powder derived via tartaric acid

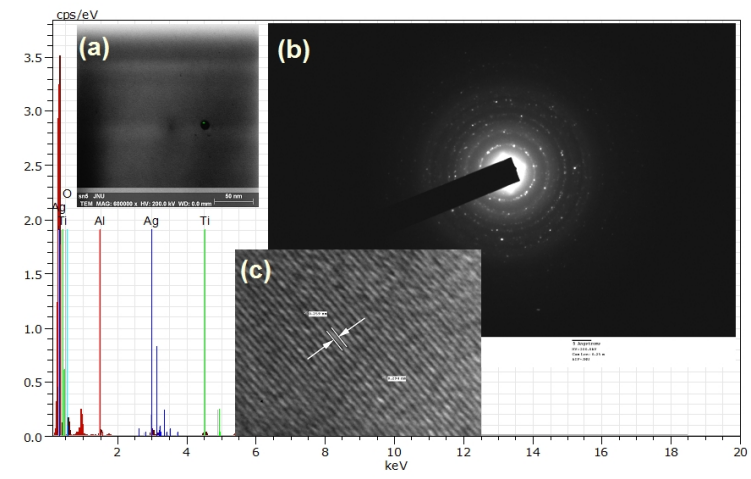

Fig. 4. EDX spectrum of $\left(\mathrm{Ag}_{1 / 2} \mathrm{Al}_{1 / 2}\right) \mathrm{TiO}_{3}$ nanoceramics. Insets: (a) TEM image, (b) SAED pattern and (c) lattice image.

gel method and calcined at $700{ }^{\circ} \mathrm{C}$ (Fig. 5). The FT-IR spectrum exhibits a prominent fundamental absorption band at $539 \mathrm{~cm}^{-1}$, which is due to Ti-O vibration. Multiple peaks (A-O absorption bands) in the frequency region of 900 to $1640 \mathrm{~cm}^{-1}$ are due to the presence of $\mathrm{Ag}-\mathrm{O}$ and $\mathrm{Al}-\mathrm{O}$ vibrations. Further, a broad and strong peak can easily be seen around $3392 \mathrm{~cm}^{-1}$, which is due to free water molecules $\left(\mathrm{H}_{2} \mathrm{O}\right.$ bands) and strong stretching (antisymmetric and symmetric) modes of the $\mathrm{OH}$ group. No other band appeared in the FT-IR spectrum clearly revealing the formation of $\left(\mathrm{Ag}_{1 / 2} \mathrm{Al}_{1 / 2}\right) \mathrm{TiO}_{3}$ after calcination at $700{ }^{\circ} \mathrm{C}$ for $5 \mathrm{~h}$.

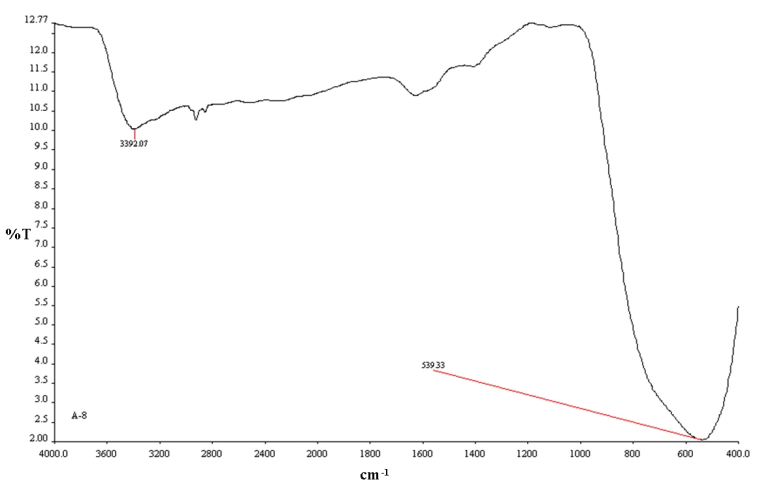

Fig. 5. FT-IR spectrum of $\left(\mathrm{Ag}_{1 / 2} \mathrm{Al}_{1 / 2}\right) \mathrm{TiO}_{3}$ nanoceramics.

Fig. 6 shows the possible mechanism involved in the soft chemical synthesis of $\left(\mathrm{Ag}_{1 / 2} \mathrm{Al}_{1 / 2}\right) \mathrm{TiO}_{3}$ nanoceramic powder using tartaric acid gel 
Table 1. The crystal data and refinement factors of $\left(\mathrm{Ag}_{1 / 2} \mathrm{Al}_{1 / 2}\right) \mathrm{TiO}_{3}$ nanoceramics obtained from X-ray powder diffraction data.

\begin{tabular}{|c|c|c|}
\hline \multicolumn{3}{|r|}{ Description of parameters: } \\
\hline Formula & $\left(\mathrm{Ag}_{1 / 2} \mathrm{Al}_{1 / 2}\right) \mathrm{TiO}_{3}$ & $\mathrm{R}_{\mathrm{p}}($ profile factor $)=100\left[\Sigma\left|\mathrm{y}_{\mathrm{i}}-\mathrm{y}_{\mathrm{ic}}\right| / \Sigma\left|\mathrm{y}_{\mathrm{i}}\right|\right]$, where \\
\hline Crystal system & Monoclinic & $y_{i}$ is the observed intensity and $y_{i c}$ is the calculated \\
\hline Space group (No.) & $\mathrm{P} 2 / \mathrm{m}(10)$ & intensity at the $\mathrm{i}^{\text {th }}$ step. \\
\hline $\mathrm{a}(\AA)$ & 4.9099 & \\
\hline $\mathrm{b}(\AA)$ & 7.5088 & $\mathrm{R}_{\mathrm{wp}}$ (weighted profile factor) $=$ \\
\hline c $(\AA)$ & 4.9063 & $100\left[\Sigma \omega_{\mathrm{i}}\left|\mathrm{y}_{\mathrm{i}}-\mathrm{y}_{\mathrm{ic}}\right|^{2} / \Sigma \omega_{\mathrm{i}}\left(\mathrm{y}_{\mathrm{i}}\right)^{2}\right]^{1 / 2}$, where $\omega_{\mathrm{i}}=1 / \sigma_{\mathrm{i}}^{2}$ \\
\hline$\beta\left({ }^{\circ}\right)$ & 91.100 & and $\sigma_{i}^{2}$ is variance of the observation. \\
\hline $\mathrm{V}\left(\AA^{3}\right)$ & 180.8460 & \\
\hline Data collection & & $\mathrm{R}_{\exp }$ (expected weighted profile factor) $=$ \\
\hline Temperature $\left({ }^{\circ} \mathrm{C}\right)$ & 24.0 & $100\left[(n-p) / \Sigma \omega_{i}\left(y_{i}\right)^{2}\right]^{1 / 2}$, where $n$ and $p$ are the \\
\hline Wavelength $[\mathrm{CuK} \alpha](\AA)$ & 1.5406 & number of profile points and refined parameters, \\
\hline Monochromator & Graphite & respectively. \\
\hline Measuring range $\left({ }^{\circ}\right)$ & $20 \leqslant 2 \theta \leqslant 80$ & \\
\hline Step $\left({ }^{\circ} 2 \theta\right)$ & 0.02 & $\mathrm{R}_{\mathrm{B}}($ Bragg factor $)=100\left[\Sigma\left|\mathrm{I}_{\mathrm{obs}}-\mathrm{I}_{\text {calc }}\right| / \Sigma\left|\mathrm{I}_{\mathrm{obs}}\right|\right]$, \\
\hline Integration time (s) & 30 & where $I_{o b s}$ is the observed integrated intensity and \\
\hline Rietveld data & & $\mathrm{I}_{\text {calc }}$ is the calculated integrated intensity. \\
\hline Program & FULLPROF & \\
\hline Function for background level & Polynomial 5-order & $\mathrm{R}_{\mathrm{F}} \quad$ (crystallographic $\quad \mathrm{R}_{\mathrm{F}}$ \\
\hline Function for peak shape & Pseudo-Voigt & $100\left[\Sigma\left|\mathrm{F}_{\text {obs }}-\mathrm{F}_{\text {calc }}\right| / \Sigma\left|\mathrm{F}_{\text {obs }}\right|\right]$, where $\mathrm{F}$ is the \\
\hline $\mathrm{R}_{\mathrm{p}}$ & 38.0 & structure factor, $\mathrm{F}=\sqrt{ }(\mathrm{I} / \mathrm{L})$, where $\mathrm{L}$ is Lorentz \\
\hline $\mathrm{R}_{\mathrm{wp}}$ & 31.1 & polarization factor. \\
\hline $\mathrm{R}_{\exp }$ & 27.3 & \\
\hline $\mathrm{R}_{\mathrm{B}}$ & 0.131 & $\chi^{2}=\Sigma \omega_{i}\left(y_{i}-y_{i c}\right)^{2}$ \\
\hline $\mathrm{R}_{\mathrm{F}}$ & 2.11 & $\mathrm{~d}($ Durbin-Watson statistics $)=\Sigma\left\{\left[\omega_{\mathrm{i}}\left(\mathrm{y}_{\mathrm{i}}-\mathrm{y}_{\mathrm{ic}}\right)-\right.\right.$ \\
\hline$x^{2}$ & 1.298 & $\left.\left.\omega_{i-1}\left(y_{i-1}-y_{i c-1}\right)\right]^{2}\right\} / \Sigma\left[\omega_{i}\left(y_{i}-y_{i c}\right)\right]^{2}$ \\
\hline d & 0.7088 & \\
\hline $\mathrm{QD}_{\mathrm{D}}$ & 1.8984 & $\mathrm{Q}_{\mathrm{D}}=$ expected $\mathrm{d}$ \\
\hline $\mathrm{S}$ & 1.1392 & $S($ goodness of fit $)=\left(R_{\mathrm{wp}} / R_{\mathrm{exp}}\right)$. \\
\hline
\end{tabular}

method. It is known that tartaric acid $\left(\mathrm{H}_{2}\right.$ Tart $)$ is energetically labile molecule. It undergoes interesting pattern of optical isomerism. Recently, mean value of heat of combustion for tartaric acid was calculated to be $1124.5 \mathrm{~kJ} / \mathrm{mol}$ [30]. In addition, the value of heat of dissociation was calculated to be $27.17 \mathrm{~kJ} / \mathrm{mol}$ for the temperature above $50{ }^{\circ} \mathrm{C}$ [31]. It clearly indicates that this energy is probably sufficient to accomplish a nano-transformation. Further, this process involves complexation of metal ions $\left(\mathrm{Ag}^{+2}, \mathrm{Al}^{+3}\right.$ and $\mathrm{Ti}^{+4}$ in this case) by polyfunctional carboxylic acids, such as tartaric acid having one hydroxyl group. Upon heating the mixture, the solvent (water) evaporates resulting in increased viscosity. After complete removal of water, the mixture turns into a gel form and its constituents are mixed at atomic level. This gel upon heating at higher temperature $\left(700{ }^{\circ} \mathrm{C}, 5 \mathrm{~h}\right)$ produces the nanoceramics: $\left(\mathrm{Ag}_{1 / 2} \mathrm{Al}_{1 / 2}\right) \mathrm{TiO}_{3}$, which might be due to the combustion of organics present in the gel, along with the evolution of gases during calcination. Therefore, the effect of such softchemical ambiance could have made the reaction to occur more easily.

UV-Vis absorption spectroscopy is a useful technique to monitor the optical properties of the quantum-sized particles. The wavelength at the maximum exciton absorption depends upon the size of the nanoparticles, which results in quantum confinements of the photogenerated electronhole carriers. Fig. 7 shows the UV-Vis spectrum of AAT-nc. Broad absorption peaks (surface plasmon resonance) are observed at $296 \mathrm{~nm}$. Also, the 


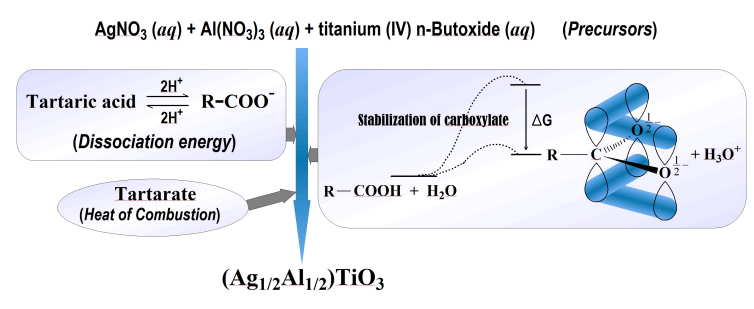

Fig. 6. Mechanism of soft chemical synthesis of $\left(\mathrm{Ag}_{1 / 2} \mathrm{Al}_{1 / 2}\right) \mathrm{TiO}_{3}$ nanoceramics using tartaric acid gel method.

plasmon bands are broadened with an absorption tail in the longer wavelengths, which may be due to the size distribution of the particles. This supports the distribution of particle sizes observed in TEM micrograph (Fig. 3).

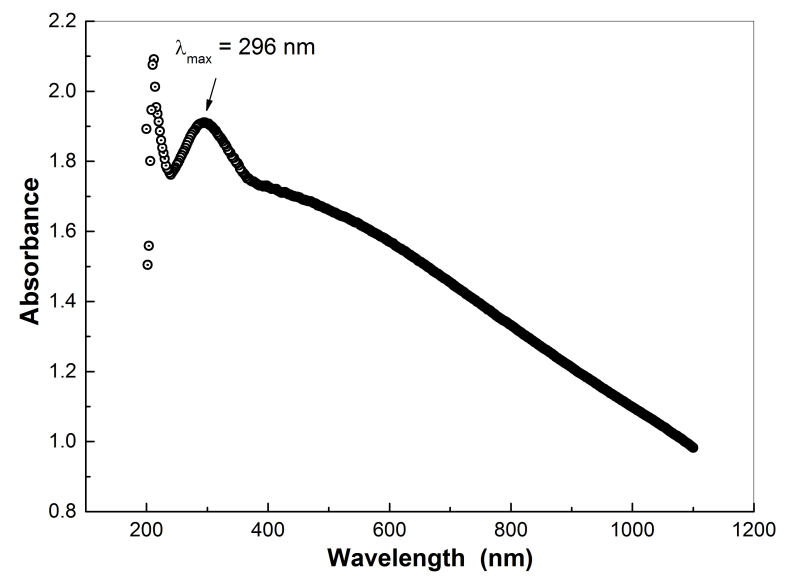

Fig. 7. UV-Vis spectrum of $\left(\mathrm{Ag}_{1 / 2} \mathrm{Al}_{1 / 2}\right) \mathrm{TiO}_{3}$ nanoceramics.

The frequency dependence of the real $\left(\varepsilon^{\prime}\right)$ and imaginary $\left(\varepsilon^{\prime \prime}\right)$ parts of dielectric constant at different temperatures are plotted in Fig. 8. It is observed that both $\varepsilon^{\prime}$ and $\varepsilon^{\prime \prime}$ follow inverse dependence on frequency. Dispersion with relatively high value of $\varepsilon^{\prime}$ can be seen in the $\varepsilon^{\prime}$-f graph in the lower frequency region and $\varepsilon^{\prime}$ drops at high frequencies. A relatively high value of $\varepsilon^{\prime}$ at low frequencies is characteristic of a dielectric material. At very low frequencies, dipoles follow the field and we have $\varepsilon^{\prime} \approx \varepsilon_{\mathrm{s}}$ (value of dielectric constant at quasi static fields). As the frequency increases, dipoles begin to lag behind the field and $\varepsilon^{\prime}$ decreases slightly. When frequency reaches the characteristic frequency, the dielectric constant drops (relaxation process) and at very high frequencies, dipoles can no longer follow the field and $\varepsilon^{\prime} \approx \varepsilon_{\infty}$.
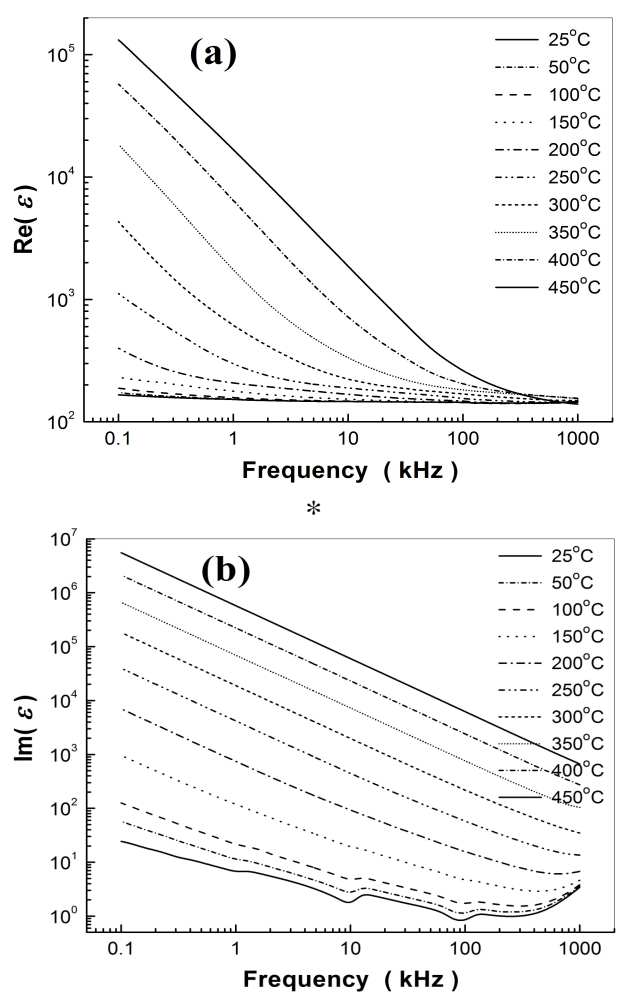

Fig. 8. Frequency dependence of (a) real and (b) imaginary parts of the dielectric constant of $\left(\mathrm{Ag}_{1 / 2} \mathrm{Al}_{1 / 2}\right) \mathrm{TiO}_{3}$ nanoceramics at different temperatures.

Fig. 9 shows the variation of dielectric constant $\left(\varepsilon^{\prime}\right)$ and loss tangent $\left(\tan \delta=\varepsilon^{\prime \prime} / \varepsilon^{\prime}\right)$ with temperature at $1 \mathrm{kHz}$. It is observed that both $\varepsilon^{\prime}$ and $\tan \delta$ increase with an increment in temperature in the working temperature range (up to $150{ }^{\circ} \mathrm{C}$ ). The values of $\varepsilon^{\prime}$ and $\tan \delta$ at room temperature are, respectively, found to be 153 and 0.043 at $1 \mathrm{kHz}$. The inset of Fig. 9 clearly illustrates that the values of $\mathrm{T}_{\mathrm{CC}}$ varies within $\pm 15 \%$ in the working temperature range (up to $+150^{\circ} \mathrm{C}$ ). Therefore, the low value of $\mathrm{T}_{\mathrm{CC}}(< \pm 15 \%), \varepsilon^{\prime}(=153)$ and low $\tan \delta\left(\sim 10^{-2}\right)$ were found in case of AAT-nc, which meets the specifications for "Z7R" of Class I dielectrics of Electronic Industries Association. Therefore, this compound may be considered as a potential candidate for capacitor applications. 


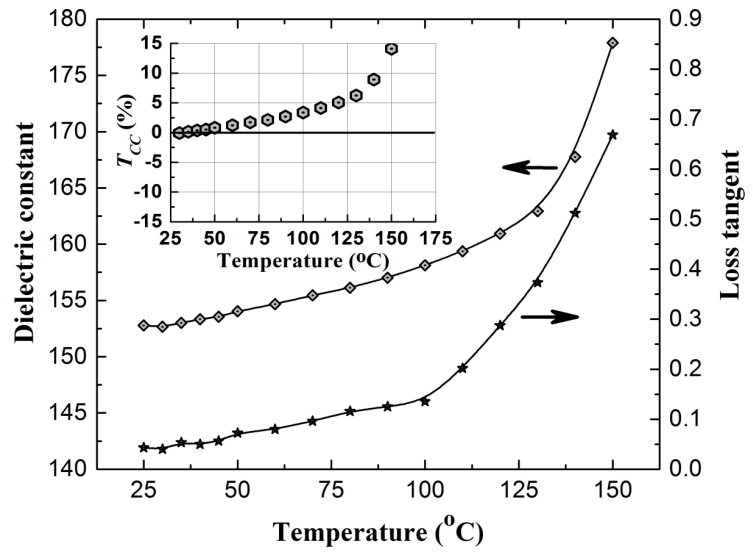

Fig. 9. Temperature dependence of dielectric constant and loss tangent of $\left(\mathrm{Ag}_{1 / 2} \mathrm{Al}_{1 / 2}\right) \mathrm{TiO}_{3}$ nanoceramics at $1 \mathrm{kHz}$. Inset: Variation of $\mathrm{T}_{\mathrm{CC}}(\%)$ with temperature at $1 \mathrm{kHz}$.

Fig. 10 shows the variation of the (a) real $\left(Z^{\prime}\right)$ and $(b)$ imaginary $\left(Z^{\prime \prime}\right)$ parts of impedance with frequency at different temperatures. It is observed that the magnitude of $Z^{\prime}$ decreases with the increase in both frequency as well as temperature, which indicates the increase in ac conductivity of the sample with increasing temperature and frequency. Besides, at low frequencies the $Z^{\prime}$ values flatten with a rise in temperature. The value of $Z^{\prime \prime}$ simply decreases with frequency at lower temperatures and at $150{ }^{\circ} \mathrm{C}$ onwards and it reaches a maximum peak $\left(\mathrm{Z}_{\max }^{\prime \prime}\right)$, which shifts to higher frequency side with an increment in temperature indicating the increasing loss in the sample. A typical peak-broadening, which is slightly asymmetrical in nature, can be observed with the rise in temperature. The broadening of peaks in frequency explicit plots of $Z^{\prime \prime}$ suggests that there is a spread of relaxation times i.e., the existence of a temperature dependent electrical relaxation phenomenon in the material. The relaxation times $(\tau)$ were calculated from the frequency, at which $Z_{\max }^{\prime \prime}$ is observed, called relaxation frequency $\left(f_{p}\right)$. At the peak, the relaxation is defined by the condition: $\omega_{\mathrm{m}} \tau_{\mathrm{m}}=1$, where $\tau_{\mathrm{m}}$ is the relaxation time. Fig. 11 shows that the relaxation frequency obeys the Arrhenius relation: $\omega_{\mathrm{m}}=\omega_{\mathrm{o}} \exp \left(-\mathrm{E}_{\tau} / \mathrm{k}_{\mathrm{B}} \mathrm{T}\right)$, where $\omega_{\mathrm{o}}$ is the preexponential factor. The activation energy, $\mathrm{E}_{\tau}$ calculated from the least squares fit to $\log \omega_{\mathrm{m}}-1 / \mathrm{T}$ data is $0.78 \mathrm{eV}$.
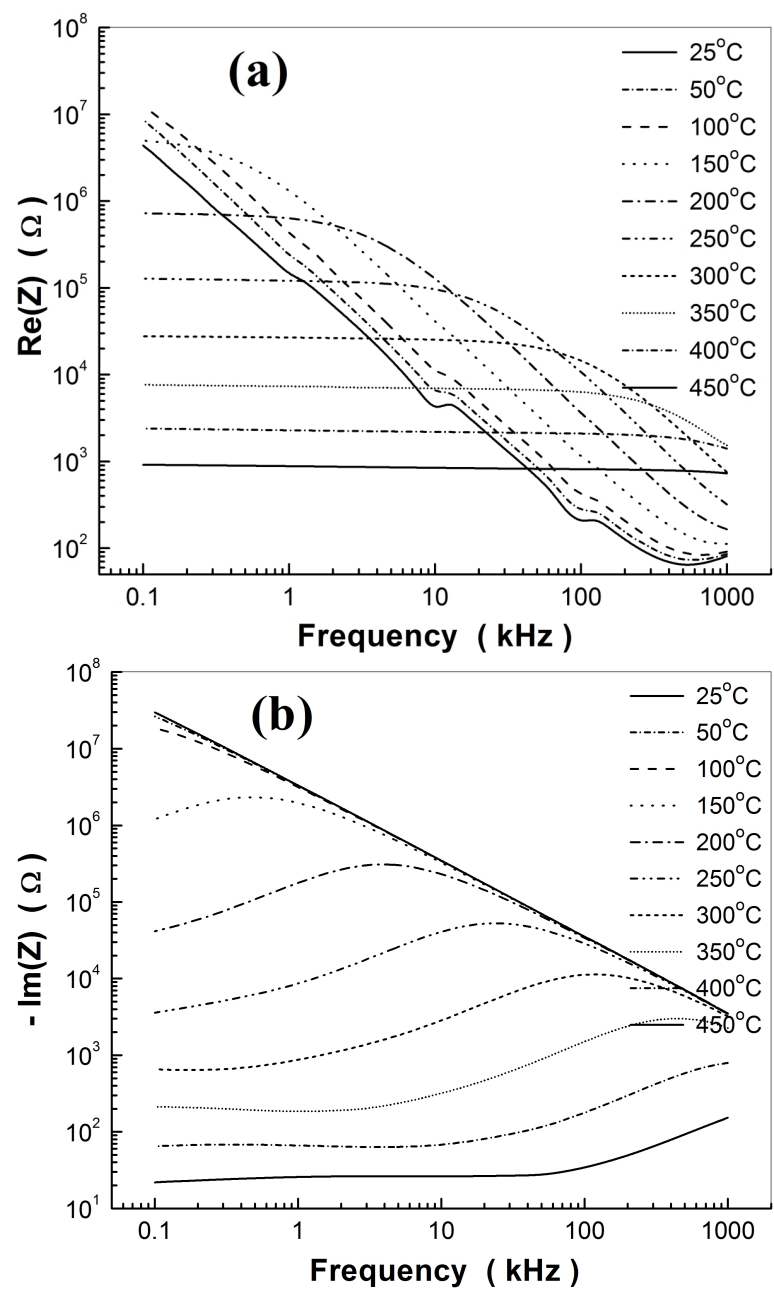

Fig. 10. Variation of (a) real and (b) imaginary parts of impedance of $\left(\mathrm{Ag}_{1 / 2} \mathrm{Al}_{1 / 2}\right) \mathrm{TiO}_{3}$ nanoceramics with frequency at different temperatures.

Fig. 12 shows a set of impedance data taken over a wide frequency range $(100 \mathrm{~Hz}$ to $1 \mathrm{MHz})$ at different temperatures as a Nyquist diagram. The impedance data at room temperature do not take the shape of a semicircle in the Nyquist plot rather present almost straight lines with a large slope, suggesting the insulating behavior of AAT-nc at room temperature. Also, it can be seen that with the increase in temperature the slope of the lines decreases and they bent towards real $\left(Z^{\prime}\right)$ axis and from $150{ }^{\circ} \mathrm{C}$ onwards, a depressed semicircle could be traced, indicating thereby an increase in the conductivity of the sample. Further, it is observed that the peak maxima of the plots decrease with 
increasing temperature and the frequency for the maximum shifts to higher values with the increase in temperature.

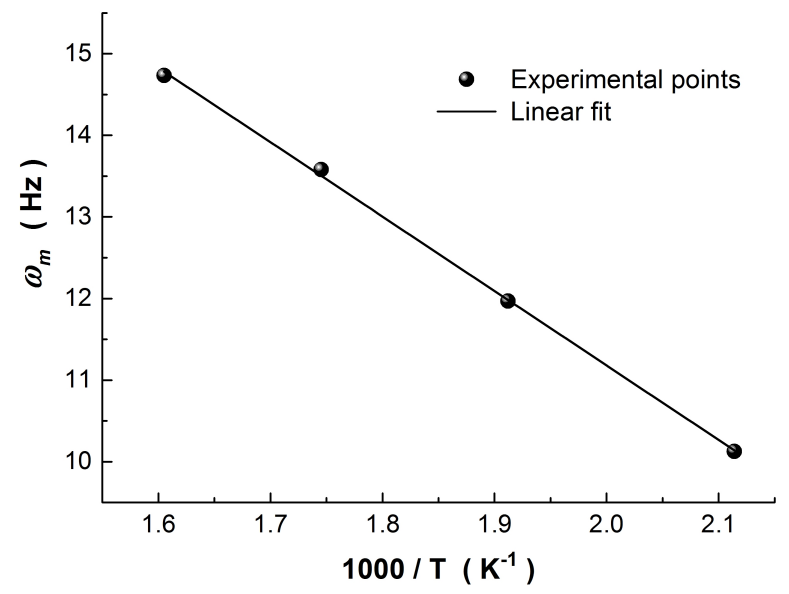

Fig. 11. Temperature dependence of relaxation frequency for $\left(\mathrm{Ag}_{1 / 2} \mathrm{Al}_{1 / 2}\right) \mathrm{TiO}_{3}$ nanoceramics. The circles are the experimental points and the solid line is the least squares straight line fit.

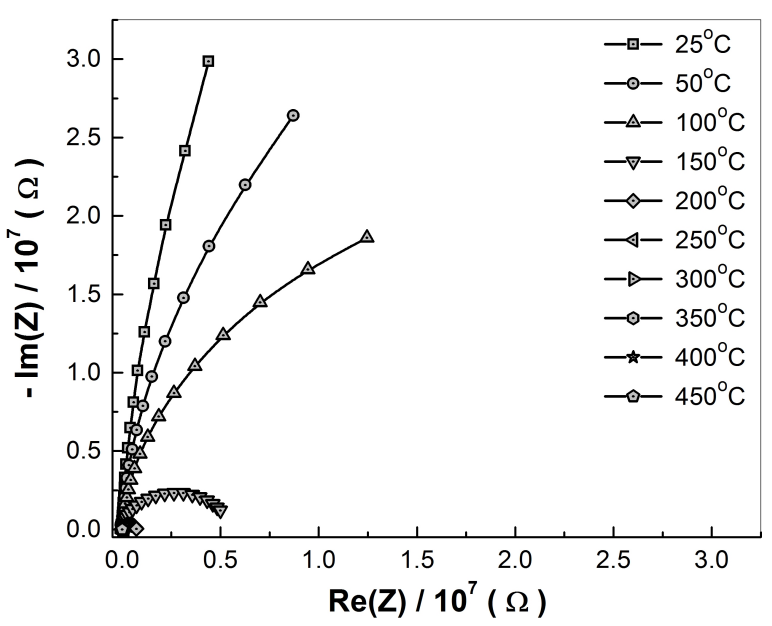

Fig. 12. Nyquist plot for $\left(\mathrm{Ag}_{1 / 2} \mathrm{Al}_{1 / 2}\right) \mathrm{TiO}_{3}$ nanoceramics at different temperatures.

Fig. 13 shows the complex impedance plot along with the fitted data at different temperatures. Complex impedance plots do not always yield perfect or depressed semicircular arcs and often the arc is asymmetric and cannot be well approximated by the combinations of impedances and capacitances only. The appropriate equivalent circuit at each temperature is illustrated in the insets of
Fig. 13. It can be seen that a constant phase element (CPE) is connected from $150{ }^{\circ} \mathrm{C}$ onwards. The parameters of each fitting, which were determined using a non-linear least-square fitting algorithm [32], are summarized in Table 2. The admittance of CPE was estimated using the relations: $\mathrm{Y}_{\mathrm{o}}=\mathrm{Q}(\mathrm{j} \omega)^{\mathrm{n}}$, where $\mathrm{Q}$ is a constant pre-factor, $\mathrm{n}$ is exponent and $\mathrm{j}=\sqrt{-1}$ is the imaginary unit. The introduction of CPE in the equivalent circuit may be due to the distribution of reaction rates and/or surface roughness. Further, all these curves do not coincide with the origin (zero value) and, hence, a series resistance has been introduced that can be ascribed to the LCR circuit representation of the sample and the value, of which increases with the increase in temperature. The impedance data do not fit well with single/double RC-combination, rather they fit excellently well with $\mathrm{R}(\mathrm{CR})$ - and $\mathrm{R}(\mathrm{C}(\mathrm{R}(\mathrm{QR})))(\mathrm{CR})$-type of equivalent circuits, respectively, for $25^{\circ} \mathrm{C}$ up to $150{ }^{\circ} \mathrm{C}$ and $150{ }^{\circ} \mathrm{C}$ onwards (insets of Fig. 13), indicating thereby that the electrical responses are due to the grain and grain boundary effects. Here, symbols R, C, and $\mathrm{Q}$ represent resistance, capacitance, and constant phase element, respectively. At higher temperatures $\left(150{ }^{\circ} \mathrm{C}\right.$ onwards) semicircles could be obtained with different values of resistance for grain and grain boundary. Hence, grain and grain boundary effects could be separated at these temperatures. These compounds are expected to lose traces of oxygen during sintering at high temperature as per the reaction [33]:

$$
\mathrm{O}_{o} \rightarrow \frac{1}{2} \mathrm{O}_{2} \uparrow+\mathrm{V}_{o}^{\bullet \bullet}+2 e^{-}
$$

These defects affect impedance and capacitance in the formation of barrier layers at the grain-grain boundary interface. During cooling of the samples after sintering reoxidation takes place. This oxidation is limited to surface and grain boundaries only due to insufficient time. This results in the difference between resistance of grain boundary and the grain itself, giving rise to the barrier. Further, it is known that for Debye type relaxation, the centre of the semicircular plots should be located on the $\mathrm{Z}^{\prime}$-axis, whereas for a non-Debye type relaxation these Argand plane plots are close to semicircular arcs with end-points on the real axis 

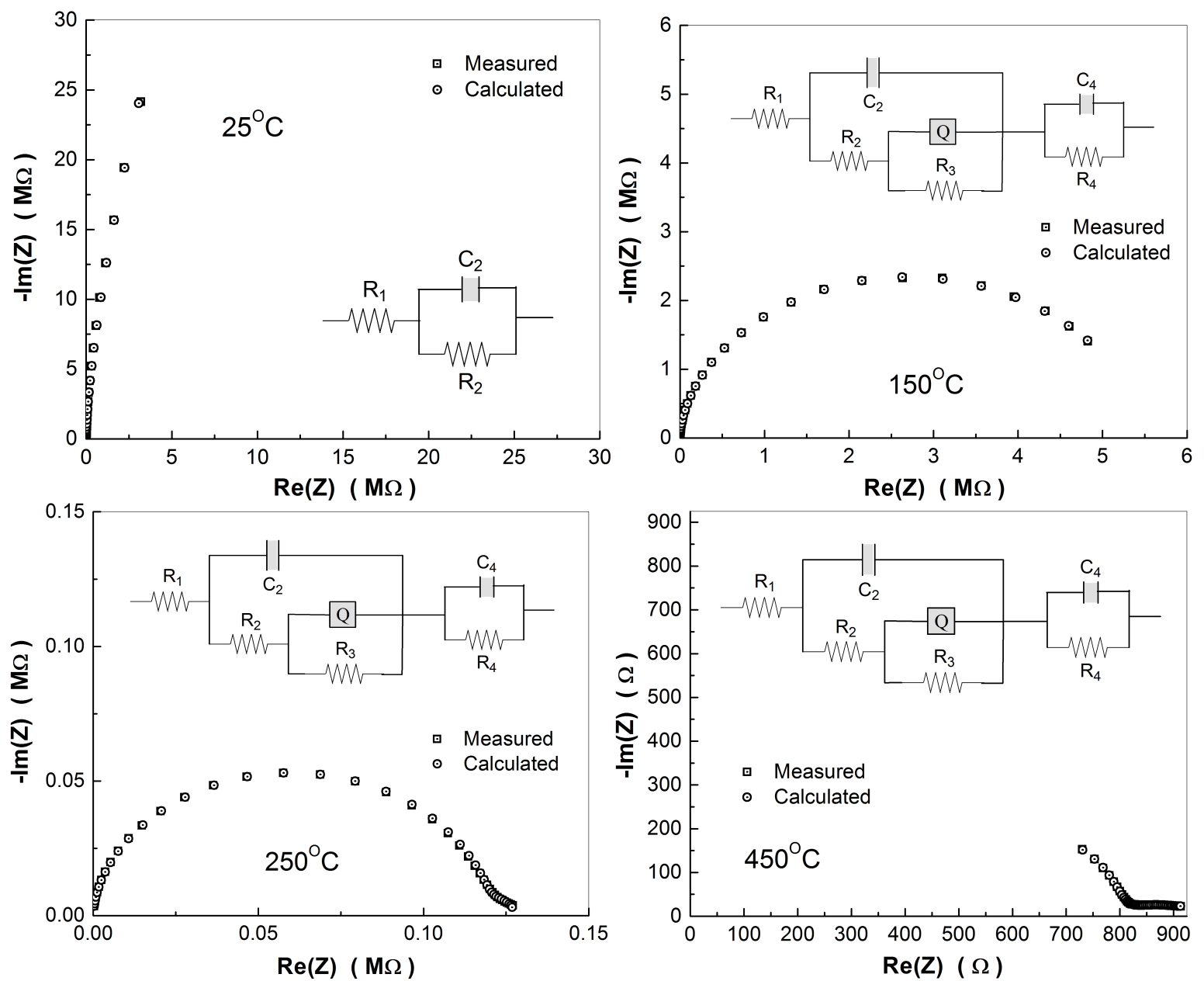

Fig. 13. Complex impedance plots (measured and calculated) of $\left(\mathrm{Ag}_{1 / 2} \mathrm{Al}_{1 / 2}\right) \mathrm{TiO}_{3}$ nanoceramics at different temperatures. Inset shows the appropriate equivalent electrical circuits.

and the centre lying below this axis. The complex impedance in such a case can be described as: $Z^{*}(\omega)=Z^{\prime}+i Z^{\prime \prime}=R /\left[1+\left(i \omega / \omega_{\mathrm{o}}\right)^{1-\alpha}\right]$, where $\alpha$ represents the magnitude of the departure of the electrical response from an ideal condition and this can be determined from the location of the centre of the semicircles. Further, it is known that when $\alpha$ approaches to zero, i.e. $\{(1-\alpha) \rightarrow 1\}$, this equation gives rise to the classical Debye's formalism. It can be seen from the impedance plots that the data are not represented by full semicircle rather they are depressed, i.e. the centres of semicircles lie little below the abscissa $\left(Z^{\prime}\right)$ axis $(\alpha>0)$, which increases with the rise in temperature, suggesting the dielectric relaxation to be of non-Debye type in the AAT-nc. This may happen due to the presence of distributed elements in the material-electrode system.

The dielectric response is expressed by a reciprocal quantity: $\mathbf{M}^{*}(\omega)=1 / \varepsilon^{*}(\omega)$, known as electric modulus, where the electrode polarization artifacts are suppressed. Typical features of $\mathbf{M}^{*}(\omega)$ include a broad, asymmetric peak in the imaginary part and a sigmoidal step in the real part. The similarity of these shapes to loss and storage of mechanical stress associated with relaxation processes is evident and has naturally led to similar interpretation. Fig. 14 shows the variation of real $\left(\mathrm{M}^{\prime}\right)$ and imaginary $\left(\mathrm{M}^{\prime \prime}\right)$ parts of electric modulus with frequency at different temperatures for AAT-nc. It is characterized by a very low value of $\mathrm{M}^{\prime}$ in the low frequency region and a sigmoidal increase in the 
Table 2. Resulting parameters of each fitting corresponding to the equivalent circuits shown in Fig. 13 for $\left(\mathrm{Ag}_{1 / 2} \mathrm{Al}_{1 / 2}\right) \mathrm{TiO}_{3}$ nanoceramics.

\begin{tabular}{ccccc}
\hline Parameters & $\mathbf{2 5}^{\circ} \mathbf{C}$ & $\mathbf{1 5 0}^{\circ} \mathbf{C}$ & $\mathbf{2 5 0}^{\circ} \mathbf{C}$ & $\mathbf{4 5 0}^{\circ} \mathbf{C}$ \\
\hline \hline $\mathrm{R}_{1}(\Omega)$ & 62.93 & 91.86 & 151.2 & 393.8 \\
$\mathrm{R}_{2}(\Omega)$ & $1.380 \times 10^{2}$ & $2.142 \times 10^{6}$ & $6.495 \times 10^{4}$ & $3.913 \times 10^{2}$ \\
$\mathrm{R}_{3}(\Omega)$ & - & $3.483 \times 10^{6}$ & $5.656 \times 10^{4}$ & $1.684 \times 10^{2}$ \\
$\mathrm{R}_{4}(\Omega)$ & - & $3.268 \times 10^{3}$ & $6.160 \times 10^{3}$ & $2.885 \times 10^{10}$ \\
$\mathrm{C}_{2}(\mathrm{~F})$ & $4.511 \times 10^{-11}$ & $4.689 \times 10^{-11}$ & $4.533 \times 10^{-11}$ & $1.691 \times 10^{-10}$ \\
$\mathrm{C}_{4}(\mathrm{~F})$ & - & $9.270 \times 10^{-10}$ & $7.475 \times 10^{-8}$ & $2.991 \times 10^{-4}$ \\
$\mathrm{CPE}, \mathrm{Q}\left(\mathrm{S} \cdot\right.$ sec $\left.^{0.5} \cdot \mathrm{cm}^{-2}\right)$ & - & $7.742 \times 10^{-10}$ & $1.569 \times 10^{-9}$ & $1.746 \times 10^{-4}$ \\
Frequency power $(\mathrm{n})$ & - & 0.66 & 0.7343 & 0.3701 \\
$\chi^{2}$ (chi squared) & 0.00226 & 0.00119 & 0.00073 & $3.222 \times 10^{-5}$ \\
\hline
\end{tabular}
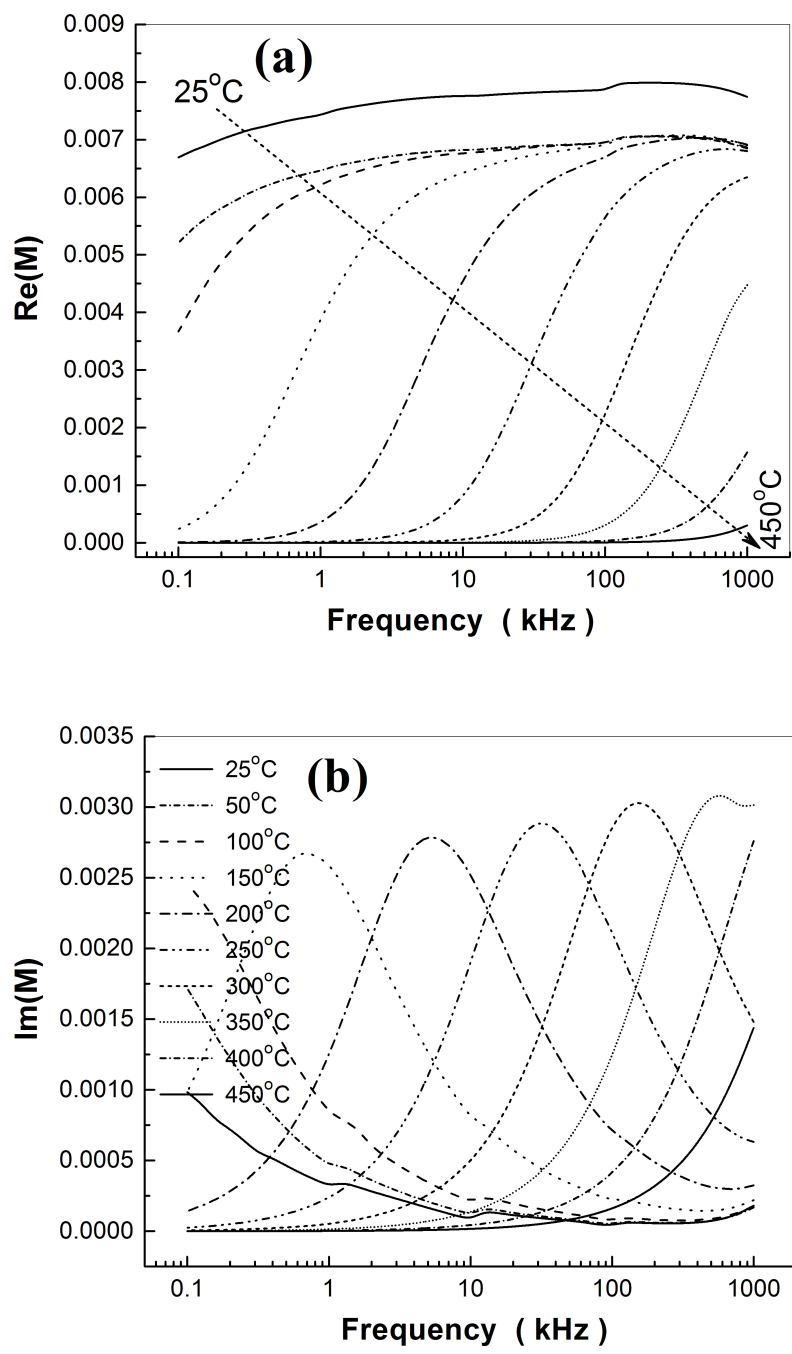

Fig. 14. Frequency dependence of real and imaginary parts of electric modulus of $\left(\mathrm{Ag}_{1 / 2} \mathrm{Al}_{1 / 2}\right) \mathrm{TiO}_{3}$ nanoceramics at different temperatures. value of $\mathrm{M}^{\prime}$ with the frequency approaching ultimately to $\mathrm{M}_{\infty}$, which may be attributed to the conduction phenomena due to short-range mobility of charge carriers. The variation $\mathrm{M}^{\prime \prime}$ as a function of frequency is characterized by: (i) clearly resolved peaks in the pattern appearing at unique frequency at different temperatures, (ii) significant asymmetry in the peaks with their positions lying in the dispersion region of $\mathrm{M}^{\prime}$ vs. frequency pattern and (iii) the peak positions have a tendency to shift towards higher frequency side with the rise in temperature. The low frequency side of the $\mathrm{M}^{\prime \prime}$ peak represents the range of frequencies, in which charge carriers can move over a long distance, i.e. charge carriers can perform successful hopping from one site to the neighbouring site. The high frequency side of the $\mathrm{M}^{\prime \prime}$ peak represents the range of frequencies, in which the charge carriers are spatially confined to their potential wells and, thus, could made localized motion within the well. The region, where a peak occurs, is an indicative of the transition from long-range to short-range mobility with increase in frequency. Further, the appearance of the peak in modulus spectrum provides a clear indication of conductivity relaxation. Also, $\mathrm{M}^{\prime \prime}(\omega)$ curves get broadened upon increasing temperature suggesting an increase in non-Debye behavior. This particular behavior seems to be unique to electrical relaxation since all other relaxation processes (e.g. mechanical, light scattering) typically exhibit opposite behavior with tendency towards Debye behavior with increasing temperature [9]. 
The ac conductivity data were obtained using a relation $\sigma^{*}(\omega)=\sigma^{\prime}(\omega)+i \sigma^{\prime \prime}(\omega)=$ $i \omega \varepsilon_{0} \varepsilon^{*}(\omega)$ and the real and imaginary part of $\sigma^{*}(\omega)$ were obtained as: $\sigma^{\prime}(\omega)=\omega \varepsilon_{o} \varepsilon^{\prime \prime}(\omega)$ and $\sigma^{\prime \prime}(\omega)=\omega \varepsilon_{o} \varepsilon^{\prime}(\omega)$. Fig. 15 shows the log-log plot of real and imaginary parts of ac electrical conductivity $\left(\sigma^{\prime}\right.$ and $\left.\sigma^{\prime \prime}\right)$ versus frequency at different temperatures. The plots of $\sigma^{\prime}$ show dispersion throughout the chosen frequency range and with the increment in temperature plots get flattened (plateau value). The switchover from the frequency-independent to the frequency-dependent regions shows the onset of the conductivity relaxation, indicating the translation from long range hopping to the short range ion-motion. Further, the real part of electrical conductivity, due to localized states, in most of the materials is expressed as Jonscher power law: $\sigma^{\prime}(\omega)=\sigma_{\mathrm{o}}+\mathrm{A} \omega^{\mathrm{s}}$, where $\sigma_{\mathrm{o}}$ is the frequencyindependent (electronic or $\mathrm{dc}$ ) part of ac conductivity, $\mathrm{s}(0 \leqslant \mathrm{~s} \leqslant 1)$ is the index, $\omega$ is an angular frequency of applied ac field and $\mathrm{A}$ is a constant, $\mathrm{e}$ is the electronic charge, $\mathrm{T}$ is the temperature, $\alpha$ is the polarizability of a pair of sites, and $\mathrm{N}$ is the number of sites per unit volume, among which hopping takes place. Such variation is associated with displacement of carriers, which move within the sample by discrete hops on the length $\mathrm{R}$ between randomly distributed localized sites. The term $A \omega^{\mathrm{s}}$ can often be explained on the basis of two distinct mechanisms for carrier conduction: (i) quantum mechanical tunneling (QMT) through the barrier separating the localized sites and (ii) correlated barrier hopping $(\mathrm{CBH})$ over the same barrier. In these models, the exponent $s$ is found to have two different trends of variation with temperature and frequency. In QMT, s is predicted to be temperature independent and is expected to show a decreasing trend with $\omega$, while for $\mathrm{CBH}$, temperature dependence of $\mathrm{s}$ should show a decreasing trend. However, the frequency dependence of conductivity, in general, does not follow the simple power law as given above but follows a double power law given as: $\sigma^{\prime}(\omega)=\sigma_{0}+A_{1} \omega^{s_{1}}+A_{2} \omega^{s_{2}}$, where $A_{1}$ and $A_{2}$ are the temperature dependent constants and $\mathrm{s}_{1}$ (characterizes the low-frequency region, corresponding to translational ion hopping) and $s_{2}$ (characterizes the high-frequency region, indicating the existence of well localized relaxation/reorientational process) are temperature as well as frequency dependent parameters. Further, it may be inferred that the slope $s_{1}$ is associated with grain-boundary conductivity, whereas $s_{2}$ depends on grain conductivity. The conductivity in the low-frequency region is associated with successful hops. Beyond the low-frequency region, many hops are unsuccessful, and as the frequency increases, more hops are unsuccessful. The change in the ratio of successful to unsuccessful hops results in dispersive conductivity and different activation energies are associated with unsuccessful and successful hopping processes. In the perovskitetype oxide materials, presence of charge traps in the band gap of the insulator is expected. The frequency and temperature dependence of ac conductivity supports the hopping-type conduction in the test material. The values of the indexes $s_{1}$ and $s_{2}$ can, respectively, be obtained from the slopes of the plots $\log \sigma^{\prime}$ vs. $\log \omega$ in the low and high frequency regions. The temperature-dependent variations of the exponents, $s_{1}$ and $s_{2}$, are shown in the inset of Fig. 15. From the plots, it is manifested that values of both $s_{1}$ and $s_{2}$ decrease with the rise in temperature and the values of $s_{1}$ always remain less than 1 . Also, the value of $\mathrm{s}_{1} \rightarrow 0$ at higher temperatures indicating that $\mathrm{dc}$ conductivity dominates at higher temperatures in the low frequency region and follows Jonscher power law. The model based on correlated hopping of electrons over barrier [34] predicts a decrease in the value of the index with the increase in temperature and the theoretical results are thus found to be consistent with the experimental results. Therefore, the electrical conduction in the system could be considered due to the short-range translational type hopping of charge carriers [34, 35]. This indicates that the conduction process is a thermally activated process. The imaginary part of the ac conductivity decreases with decreasing frequency. Therefore, the conductivity representation supports the electronic conduction.

Based on CBH model the ac conductivity data have been used to evaluate the density of states at 


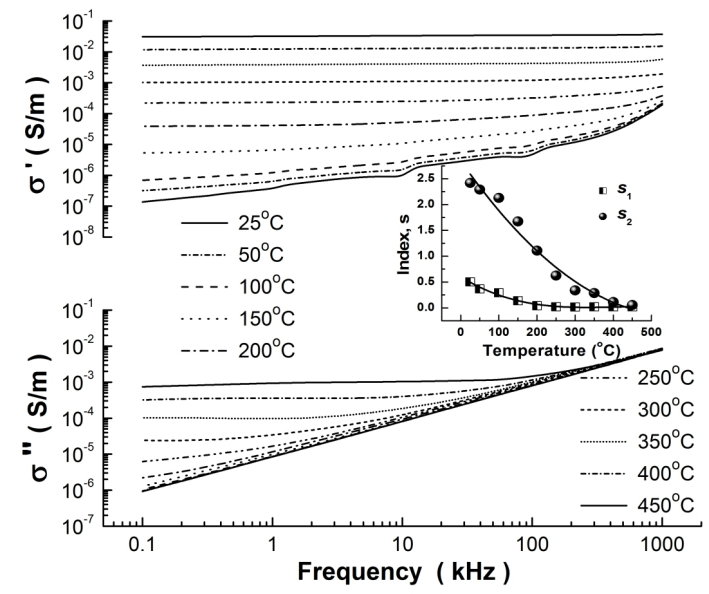

Fig. 15. Variation of ac conductivity with frequency at different temperatures of $\left(\mathrm{Ag}_{1 / 2} \mathrm{Al}_{1 / 2}\right) \mathrm{TiO}_{3}$ nanoceramics. Inset: Temperature dependence of low- and high-frequency hopping parameters $\left(\mathrm{s}_{1}\right.$ and $\left.\mathrm{s}_{2}\right)$.

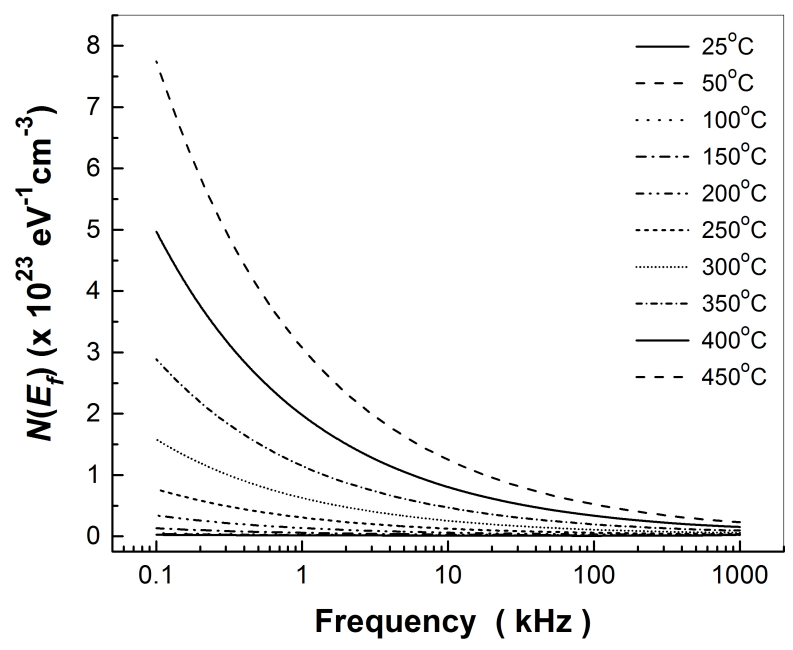

Fig. 16. Frequency dependence of $\mathrm{N}\left(\mathrm{E}_{\mathrm{f}}\right)$ of $\left(\mathrm{Ag}_{1 / 2} \mathrm{Al}_{1 / 2}\right) \mathrm{TiO}_{3}$ nanoceramics at different temperatures.

Fermi level $\mathrm{N}\left(\mathrm{E}_{\mathrm{f}}\right)$ using the relation [36]: $\sigma^{\prime}(\omega)=$ $(\pi / 3) \mathrm{e}^{2} \omega \mathrm{k}_{\mathrm{B}} \mathrm{T}\left\{\mathrm{N}\left(\mathrm{E}_{\mathrm{f}}\right)\right\}^{2} \alpha^{-5}\left\{\ln \left(\mathrm{f}_{\mathrm{o}} / \omega\right)\right\}^{4}$, where $\mathrm{f}_{\mathrm{o}}$ the photon frequency and $\alpha$ is the localized wave function, assuming $\mathrm{f}_{\mathrm{o}}=10^{13} \mathrm{~Hz}$, the polarizability $\alpha=10^{10} \mathrm{~m}^{-1}$ at various operating frequencies and temperatures. Fig. 16 illustrates the frequency dependence of $\mathrm{N}\left(\mathrm{E}_{\mathrm{f}}\right)$ at different temperatures. It can be seen that the value of $\mathrm{N}\left(\mathrm{E}_{\mathrm{f}}\right)$ decreases with the increase in the operating frequency for all temperatures and it simply increases with the increase in temperature for all the frequencies. Therefore, at low frequencies the electrical conduction in the system is affected by both frequency as well as temperature, whereas at higher frequencies the charge carriers are localized and being affected by thermal excitations. The reasonably high values of $N\left(E_{f}\right)$ suggest that the hopping between the pairs of sites dominates the mechanism of charge transport in AAT-nc.

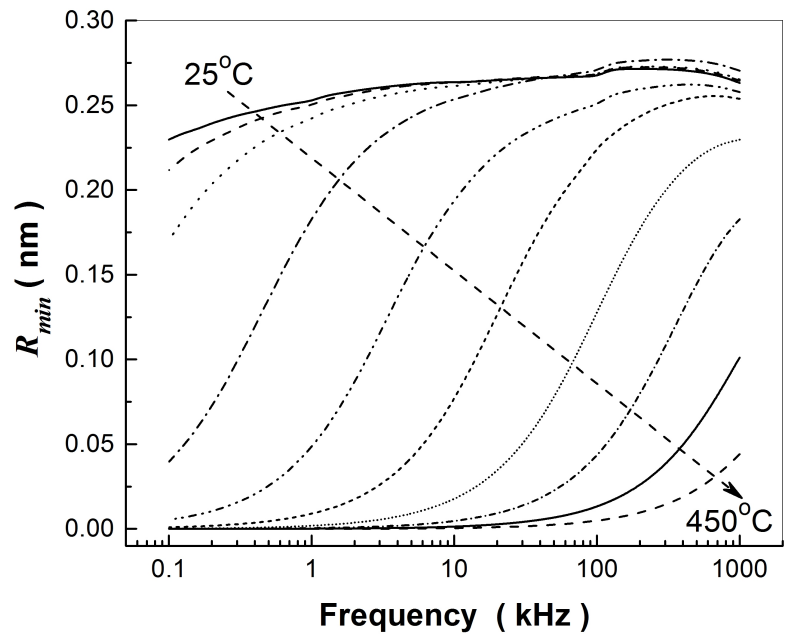

Fig. 17. Frequency dependence of $R_{\min }$ of $\left(\mathrm{Ag}_{1 / 2} \mathrm{Al}_{1 / 2}\right) \mathrm{TiO}_{3}$ nanoceramics at different temperatures.

The minimum hopping length, $R_{\min }$ was estimated using the relation [37]: $\mathrm{R}_{\min }=2 \mathrm{e}^{2} / \pi \varepsilon \varepsilon_{\mathrm{o}} \mathrm{W}_{\mathrm{m}}$, where $\mathrm{W}_{\mathrm{m}}=6 \mathrm{k}_{\mathrm{B}} \mathrm{T} /(1-\mathrm{s})$ is the binding energy. Fig. 17 shows the variation of $\mathrm{R}_{\min }$ with frequency at various temperatures. It is characterized by a very low value $\left(\sim 10^{-10} \mathrm{~m}\right)$ of $\mathrm{R}_{\min }$ in the lower frequency region, a continuous dispersion with the increase in frequency, having a tendency to saturate at a maximum asymptotic value in the higher frequency region. Such observations may possibly be related to a lack of restoring force governing the mobility of charge carriers under the action of an induced electric field. This behavior supports the long-range mobility of charge carriers. Further, a sigmoidal increase in the value of $R_{\min }$ with the frequency approaching ultimately to a saturation value may be attributed to the conduction phenomenon due to 
the short-range mobility of charge carriers. Further, it can be seen that the values of $R_{\text {min }}$ decrease with a rise in temperature.

\section{Conclusions}

In summary, the present soft-chemical method is truly a green cost-effective approach, capable of synthesizing $\left(\mathrm{Ag}_{1 / 2} \mathrm{Al}_{1 / 2}\right) \mathrm{TiO}_{3}$ nanoceramic powder. AAT nanoceramic powder was found to have a perovskite-type monoclinic structure with the particle sizes of 2 to $7.5 \mathrm{~nm}$. EDX and FT-IR studies confirmed the formation of pure AAT. Heat of combustion, heat of dissociation of tartaric acid and combustion of organics present in the gel along with the evolution of gases during calcination created the ambiance for reaction to occur more easily to form AAT-nc. UV-Vis study exhibited the surface plasmon resonance at $296 \mathrm{~nm}$. The dielectric relaxation was found to be of non-Debye type. Electric modulus studies supported the hopping type of conduction in AAT-nc. The ac conductivity was found to obey the universal power law. The pair approximation type correlated barrier hopping model was found to successfully explain the mechanism of charge transport in AAT-nc. Further, a low value of dielectric constant $(=153)$, loss tangent $(=0.043)$ at $1 \mathrm{kHz}$ and a low $\mathrm{T}_{\mathrm{CC}}(< \pm 15 \%)$ in the working temperature range (up to $150{ }^{\circ} \mathrm{C}$ ) makes this material suitable for capacitor application and may be designated as ' $\mathrm{Z} 7 \mathrm{R}$ ' Class I material as per the specifications of the Electronic Industries Association.

\section{Acknowledgements}

Authors gratefully acknowledge Dr. G.S. Saini, Advanced Research Instrumentation Centre, Jawaharlal Nehru University, New Delhi for providing the EDX pattern and TEM image and Dr. A. Narayan, Patna University, Patna, India for arranging the XRD data.

\section{References}

[1] Eichel R.-A., Kungl H., Funct. Mater. Lett., 3 (2010), 1.

[2] Damuanovic D., Klein N., Li J., Porokhonskyy V., Funct. Mater. Lett., 3 (2010), 5.

[3] Leontsev S.O., Eitel R.E., Sci. Technol. Adv. Mater., 11 (2010), 044302.
[4] Rödel J., Jo W., Seifert K.T.P., Anton E.-M., Granzow T., Damuanovic D., J. Am. Ceram. Soc., 92 (2009), 1153.

[5] Shrout T.R., Zhang S.J., J. Electroceram., 19 (2007), 111.

[6] Takenaka T., Nagata H., J. Eur. Ceram. Soc., 25 (2005), 2693.

[7] Cross L.E., Nature, 432 (2004), 24.

[8] Smolenskit G.A., Isupov V.A., Agranovskaya A.I., Krainik N.N., Sov. Phys. Solid State, 2 (1961), 2651.

[9] Prasad K., Kumari K., Lily, Chandra K.P., YADAV K.L., SEN S., Adv. Appl. Ceram., 106 (2007), 241.

[10] Hiruma Y., Nagata H., Takenaka T., J. Appl. Phys., 105 (2009), 084112.

[11] Inaguma Y., Katsumata T., Wang R., Kobashi K., Itoh M., Shan Y.-J., NAKAMURA T., Ferroelectrics, 264 (2001), 127.

[12] Park J.-H., Woodward P.M., PARise J.B., Reeder R.J., Lubomirsky I., Stafsudd O., Chem. Mater., 11 (1999), 177.

[13] Kumar S., Sahay L.K., Jha A.K., Prasad K., $A d v$. Mater. Lett., 5 (2014), 67.

[14] Kumar S., Sahay L.K., Jha A.K., Prasad K., $A d v$. Nano Res., 1 (2013), 211.

[15] Raevskit I.P., ReZnichenko L.A., Malitskaya M.A., Tech. Phys. Lett., 26 (2000), 93.

[16] Liao Y., Xiao D., Lin D., Appl. Phys. A-Mater. Sci. Process., 90 (2008), 165.

[17] Wu L., Xiao D., Zhou F., Teng Y., Li Y., J. Alloy. Compd., 509 (2011), 466.

[18] LU Y., Li Y., WANG D., Yin Q., Ferroelectrics, 358 (2007), 109.

[19] Lu Y., Li Y., Wang D., Wang T., YIn Q., J. Electroceram., 21 (2008), 309.

[20] Tang X.-G., Wang J., Wang X.-X., Chan H.L.W., Chem. Mater., 16 (2004), 5293.

[21] Maeda T., Takiguchi N., Ishikawa M., Hemsel T., Morita T., Mater. Lett., 64 (2010), 125.

[22] Lencka M.M., Oledzka M., Riman R.E., Chem. Mater., 12 (2000), 1323.

[23] JHA A.K., Prasad K., Colloid. Surface. B, 75 (2010), 330.

[24] JHA A.K., PRASAD K., Integr. Ferroelectr., 117 (2010), 49.

[25] Chen W., Kume S., Watari K., Mater. Lett., 59 (2005), 3238.

[26] Sen S., Sahu P., Prasad K., Mater. Sci.-Poland, 28 (2010), 265.

[27] Hao J., Wang X., Chen R., Li L., Mater. Chem. Phys., 90 (2005), 282.

[28] Xu Q., Chen S., Chen W., Huang D., Zhou J., SUN H., LI Y., J. Mater. Sci., 41 (2006), 6146.

[29] Xu Q., Chen X., Chen W., Chen S., Kim B., Lee J., Mater. Lett., 59 (2005), 2437.

[30] Kochergina L.A., Volkov A.V., Krutov D.V., Krutova O.N., Russ. J. Phys. Chem. A, 80 (2006), 899. 
[31] Bates R.G., Canham R.G., J. Res. Natl. Bur. Stand., 47 (1951), 343.

[32] BoukAmp B.A., Solid State Ionics, 169 (2004), 65.

[33] KrÖGER F.A., VInK H.J., Solid State Phys., 3 (1956), 307.

[34] Elliott S.R., Philos. Mag. B, 37 (1978), 553.

[35] Funke K., Prog. Solid State Chem., 22 (1993), 111.
[36] Sharma G.D., Roy M., Roy M.S., Mater. Sci. Eng. $B, 104$ (2003), 15.

[37] Nadeem M., Akhtar M.J., Khan A.Y., Shaheen R., Haque M.N., Chem. Phys. Lett. 366 (2002), 433.

Received 2014-05-16 Accepted 2014-10-12 